\title{
Configurações
}

Revista Ciências Sociais

\section{O apadrinhamento civil como alternativa ao acolhimento permanente de crianças e jovens}

Civil patronage as an alternative to the permanent residential care of children Le parrainage civil come alternative au placement durable des enfants en établissement d'accueil

\section{Elisabete Ferreira}

\section{(2) OpenEdition}

\section{Journals}

\section{Edição electrónica}

URL: http://journals.openedition.org/configuracoes/7255

DOI: 10.4000/configuracoes.7255

ISSN: 2182-7419

\section{Editora}

Centro de Investigação em Ciências Sociais

Edição impressa

Paginação: 159-176

ISSN: 1646-5075

Refêrencia eletrónica

Elisabete Ferreira, « $\mathrm{O}$ apadrinhamento civil como alternativa ao acolhimento permanente de crianças e jovens ", Configurações [Online], 23 | 2019, posto online no dia 28 junho 2019, consultado o 10 dezembro 2020. URL : http://journals.openedition.org/configuracoes/7255 ; DOI : https://doi.org/ 10.4000/configuracoes.7255 
Ferreira, Elisabete - 0 apadrinhamento civil como alternativa ao acolhimento permanente de crianças e jovens. Configurações, vol. 23, 2019, pp. 159-176.

\title{
0 apadrinhamento civil como alternativa ao acolhimento permanente de crianças e jovens
}

\author{
ELISABETE FERREIRA*
}

Universidade Católica Portuguesa

\begin{abstract}
Resumo
Idealmente, as crianças deveriam permanecer durante toda a sua infância junto dos seus progenitores, mas quando estes, por ação ou omissão, as colocam em perigo, o Estado deve intervir. A Lei de Proteção às Crianças e Jovens em Perigo consagra medidas de proteção a executar em meio natural de vida e medidas de colocação. Mas muitas crianças acabam por permanecer em acolhimento residencial até à maioridade. $\mathrm{O}$ instituto do apadrinhamento civil foi concebido como alternativa à institucionalização de longa duração, mas permanece quase desconhecido e muito pouco aplicado. O presente trabalho procura divulgar este instituto e apresentar uma curta reflexão sobre as suas potencialidades e fragilidades.
\end{abstract}

Palavras-chave: Apadrinhamento civil, crianças e jovens, sistema de proteção, institucionalização.

\footnotetext{
Abstract

Civil patronage as an alternative to the permanent residential care of children Ideally, children should remain with their parents throughout their entire childhood. However, when parents violate their parental obligations towards their children, whether that occurs by action or omission, the State should intervene. The Law on Protection of endangered Children and Youth conceives protection measurements to be executed within the child's natural environment and residential and foster care. Many children remain in residential care until they reach the legal age. Though the civil patronage was created to become an alternative to the long term residential care of children,

*E-mail: mferreira@porto.ucp.pt
} 
it remains pretty much unknown and very seldom applied. The present paper's goal is to present the civil patronage and question its main virtues and faults.

Keywords: Civil patronage, children and youth, protection system, residential care

\begin{abstract}
Résumé
Le parrainage civil come alternative au placement durable des enfants en etablissement d'accueil

Idéalement, les enfants devrez se maintenir avec ses parents pendant toute l'enfance, mais quand les parents sont en violation des ses obligations parentales, pour action o omission, l'Etat est obligé à intervenir. La Loi de Protection des Enfants et Jeunes en danger consacre des mesures de protection a exécuter dans le moyen naturel de vie de l'enfant y mesures de placement. Beaucoup d'enfants restent en placement dans établissement d'accueil jus 'qua l'âge légale. Le parrainage civil a été construit pour devenir une alternative au placement en établissement d'accueil de longue duration, mais cet institut reste presque inconnu et peu appliqué. Ce travail veut présenter le parrainage civil et offre le discussion a propos de ses points positifs e négatifs.
\end{abstract}

Mots-clés: Parrainage civil, enfants et jeunes, système de protection, placement en établissement d'accueil.

\title{
1. Introdução
}

Adotada pela Assembleia Geral nas Nações Unidas em 20 de novembro de 1989 e ratificada pelo Estado português em 21 de setembro de 1990, a Convenção sobre os Direitos das Crianças ${ }^{1}$, reconhecendo que a criança, para o desenvolvimento harmonioso da sua personalidade, deve crescer num ambiente familiar, em clima de felicidade, amor e compreensão, determina, no seu o artigo $9^{\circ}$ que:

1. Os Estados Partes garantem que a criança não é separada de seus pais contra a vontade destes, salvo se as autoridades competentes decidirem, sem prejuizo de revisão judicial e de harmonia com a legislação e o processo aplicáveis, que essa separação é necessária no interesse superior da criança. Tal decisão pode mostrar-se necessária no caso de, por exemplo, os pais maltratarem ou negligenciarem a criança ou no caso de os pais viverem separados e uma decisão sobre o lugar da residência da criança tiver de ser tomada.

2. Em todos os casos previstos no $n .^{\circ} 1$ todas as partes interessadas devem ter a possibilidade de participar nas deliberações e de dar a conhecer os seus pontos de vista.

3. Os Estados Partes respeitam o direito da criança separada de um ou de ambos os seus pais de manter regularmente relações pessoais 
e contactos diretos com ambos, salvo se tal se mostrar contrário ao interesse superior da criança.

O artigo $20^{\circ}$ da CDC determina a necessidade de proteção da criança privada de ambiente familiar e a obrigação do Estado de assegurar proteção especial à criança privada do seu ambiente familiar e de zelar para que possa beneficiar de cuidados alternativos adequados ou colocação em instituições apropriadas, devendo todas as medidas relativas a esta obrigação ter devidamente em conta a origem cultural da criança.

Por sua vez, a Constituição da República Portuguesa ${ }^{2}$, no seu artigo $36^{\circ}$, n. ${ }^{\circ}$ s 5 e 6 , consagra o direito/dever dos pais à educação e manutenção dos filhos e, correspetivamente, à inseparabilidade destes dos respetivos pais, salvo quando estes não cumpram os seus deveres fundamentais para com eles e sempre mediante decisão judicial. No artigo $69^{\circ}$, está consagrada a proteção à Infância, como segue:

1. As crianças têm direito à proteção da sociedade e do Estado, com vista ao seu desenvolvimento integral, especialmente contra todas as formas de abandono, de discriminação e de opressão e contra o exercício abusivo da autoridade na família e nas demais instituições.

2. O Estado assegura especial proteção às crianças órfãs, abandonadas ou por qualquer forma privadas de um ambiente familiar normal.

3. (...)

Assim, e como é sabido, idealmente, as crianças deveriam permanecer durante toda a sua infância junto dos seus progenitores. Porém, tal desiderato nem sempre é possível e cabe ao Estado encontrar alternativas viáveis, de modo a que as crianças possam alcançar o seu pleno desenvolvimento e tenham condições para prosseguir um projeto de vida de sucesso.

Nos nossos dias, a Lei de Proteção de Crianças e Jovens em Perigo ${ }^{3}$ determina que a intervenção para promoção dos direitos e proteção da criança e do jovem em perigo tenha lugar quando os pais, o representante legal ou quem tenha a guarda de facto ponham em perigo a sua segurança, saúde, formação, educação ou desenvolvimento, ou quando esse perigo resulte de ação ou omissão de terceiros ou da própria criança ou do jovem a que aqueles não se oponham de modo adequado a removê-lo. Considera-se que a criança ou o jovem está em perigo quando: esteja abandonada ou viva entregue a si própria; sofra maus tratos físicos ou psíquicos ou seja vítima de abusos sexuais; não receba os cuidados ou a afeição adequados à sua idade e situação pessoal; esteja aos 
cuidados de terceiros, durante período de tempo em que se observou o estabelecimento com estes de forte relação de vinculação e em simultâneo com o não exercício, pelos pais, das suas funções parentais; seja obrigada a atividades ou trabalhos excessivos ou inadequados à sua idade, dignidade e situação pessoal ou prejudiciais à sua formação ou desenvolvimento; esteja sujeita, de forma direta ou indireta, a comportamentos que afetem gravemente a sua segurança ou o seu equilíbrio emocional; ou assuma comportamentos ou se entregue a atividades ou consumos que afetem gravemente a sua saúde, segurança, formação, educação ou desenvolvimento sem que os pais, o representante legal ou quem tenha a guarda de facto se lhes oponham de modo adequado a remover essa situação.

As propostas de intervenção que decorrem desta lei representam soluções de natureza transitória para este problema. Muitas vezes, e como veremos em seguida, a situação de perigo para a criança desaparece ao fim de alguns meses de trabalho das Comissões de Proteção de Crianças e Jovens com o agregado familiar. Noutros casos, impõe-se a opção por medidas mais interventivas, por vezes desenraizantes da criança do seu meio natural de vida, por períodos limitados de tempo. Em situações limite, o afastamento da família biológica tornar-se-á permanente e não restará à criança outro projeto de vida que não seja o da residencialização, caso seja inviável o encaminhamento para a adoção.

As alterações de 2015 à LPCJP vieram claramente dar prioridade às soluções que passem pela integração da criança em perigo numa família, seja ela a sua família biológica, ou uma outra família que se encontre disponível para acolhê-la, em detrimento das soluções que esta lei denomina agora como de acolhimento residencial, por contraposição à anterior terminologia adotada de acolhimento em instituição.

No presente trabalho pretendemos trazer luz à reflexão sobre a importância do instituto do apadrinhamento civil como alternativa ao acolhimento permanente de algumas crianças, não deixando de apontar as suas principais fragilidades, que obstam a que possa verdadeiramente realizar o potencial para o qual foi idealizado.

\section{Enquadramento geral do sistema de promoção e proteção portu- guês: a LPCJP; princípios orientadores da intervenção; medidas de promoção e proteção}

"Portugal tem hoje um edifício legislativo de inegável ambição no que diz respeito ao Direito de Menores" (Martinho, 2009: 275). O atual sistema de promoção de direitos e de proteção das crianças em perigo, plasmado na LPCJP, traduz-se num modelo de intervenção misto, em que encontramos, por um lado, a possibilidade de recurso à via judiciária e, por outro, com preferência 
sobre a primeira, uma ação formal não judiciária, em que ocupa lugar de destaque a figura das comissões de proteção de crianças e jovens em perigo.

Até à entrada em vigor da LPCJP, pese embora as sucessivas reformas operadas no sistema de proteção de menores, poderíamos classificar tal sistema como paternalista e monolítico, pouco sensível aos direitos fundamentais das crianças e seus progenitores (Clemente, 2009:15). Mas a característica essencial deste modelo - e a mais polémica (Bravo, 2002: 211) - decorria da igual forma de tratamento do adolescente delinquente e da criança colocada em perigo, quanto à sua vida, integridade física ou mesmo socialização, pelos mais diversos fatores.

A LPCJP de 1999 representa uma rutura com o anterior sistema de proteção, influenciada pelo contexto internacional em que surge e pela convicção entretanto criada, também a nível internacional, da importância da colaboração da sociedade com o Estado, na assunção de responsabilidades ao nível da promoção e proteção dos direitos das suas crianças, aproveitando-se as dinâmicas de proximidade de cada comunidade. A LPCJP veio refundar o sistema de intervenção judicial e administrativo relativo aos menores, criando um novo modelo de intervenção, alicerçado nas tendências recentes, que colocam a tónica na promoção dos direitos das crianças e dos jovens (Clemente, 2009: 21). A LPCJP institucionaliza um sistema global de proteção, regulando a intervenção social do Estado e da comunidade, reservando a intervenção dos Tribunais para os casos de ausência de consentimento, ou quando é necessário decidir sobre restrições ou regulação do exercício de direitos (Rodrigues, 2003: 56).

A LPCJP tem como âmbito subjetivo de aplicação as crianças e jovens em perigo. Esta lei visa a promoção dos direitos e a proteção das crianças e dos jovens em perigo, que residam ou se encontrem ocasionalmente em território nacional, independentemente da sua nacionalidade, por forma a garantir o seu bem-estar e desenvolvimento integral. A formulação legal aderiu ao conceito jurídico de crianças e jovens em perigo, inspirado no artigo $1918 .^{\circ}$ do Código Civil, em detrimento do conceito mais amplo de "crianças em risco", dado que nem todos os riscos para o desenvolvimento da criança legitimam a intervenção do Estado e da sociedade na sua vida, autonomia e família. Limita-se, assim, a intervenção às situações de risco que ponham em perigo a segurança, a saúde, a formação, a educação ou o desenvolvimento da criança, ou do jovem. A noção legal de perigo abrange um conjunto de situações muito variadas, que vão desde a criança agredida fisicamente, à privada de afeto da família, à criança ou jovem violentado sexualmente, àquela que se prostitui ou que consome, com gravidade, estupefacientes, à que se alcooliza, à que é absentista escolar, porque é chamada a trabalhar, para sustentar pais e irmãos, à que mendiga por ordem de quem tem a sua guarda, etc. (Carreira, 2002: 26). 
A intervenção de promoção e proteção com crianças e jovens, que se encontram nas situações previstas nesta lei, funda-se no artigo 69. ${ }^{\circ}$ da Constituição, que confere à sociedade e ao Estado o dever de os proteger contra todas as formas de abandono, de discriminação e opressão e contra o exercício abusivo da autoridade, com vista ao seu desenvolvimento integral, mas também no artigo $19^{\circ} \mathrm{da}$ CDC.

Estabelecem-se, como princípios orientadores da intervenção no âmbito da LPCJP, os princípios do superior interesse da criança e do jovem, da privacidade, da intervenção precoce, mínima, proporcional e atual, da responsabilidade parental, do primado da continuidade das relações psicológicas profundas, da prevalência da família, da obrigatoriedade da informação, da audição obrigatória e da participação e subsidiariedade. No que concerne ao princípio da prevalência da família, resulta desde a alteração à LPCJP de 2015, um conteúdo mais abrangente para este princípio, na medida em que, na nova alínea h), relativa ao princípio da prevalência da família, se adverte expressamente para a necessidade de integração da criança ou jovem em perigo em família, quer na sua família biológica, quer promovendo a sua adoção ou outra forma de integração familiar estável. Com a Lei n. ${ }^{\circ}$ 142/2015, de 8 de setembro, foi introduzido o novo princípio, constante na alínea g), do primado da continuidade das relações psicológicas profundas, que determina que a intervenção deve respeitar o direito da criança à preservação das relações afetivas estruturantes de grande significado e de referência para o seu saudável e harmónico desenvolvimento, devendo prevalecer as medidas que garantam a continuidade de uma vinculação secularizante.

As medidas de promoção dos direitos e de proteção das crianças e dos jovens em perigo previstas na LPCJP visam: o afastamento do perigo em que estes se encontram; proporcionar-lhes as condições que permitam proteger e promover a sua segurança, saúde, formação, educação, bem-estar e desenvolvimento integral; finalmente, a garantia da recuperação física e psicológica das crianças e jovens, vítimas de qualquer forma de exploração, ou abuso. Dividem-se em dois grandes grupos: as medidas a executar em meio natural de vida e as medidas de colocação. São, designadamente: o apoio junto dos pais, o apoio junto de outro familiar, a confiança a pessoa idónea, o apoio para a autonomia de vida, o acolhimento familiar, o acolhimento residencial, a confiança a pessoa selecionada para a adoção, a família de acolhimento ou a instituição, com vista a futura adoção, nos termos do artigo $35 .^{\circ}$ da LPCJP. As quatro primeiras são consideradas medidas a aplicar em meio natural de vida, enquanto que o acolhimento familiar e o acolhimento residencial já se consideram medidas de colocação. Por sua vez, a confiança com vista a adoção será classificada como medida a executar em meio natural de vida quando a confiança seja atribuída a pessoa selecionada para adoção, enquanto nos restantes casos tratar-se-á de medida de colocação. Esta lei, ao contrário do que sucedia 
com a lei anterior, tipifica as medidas de promoção e proteção aplicáveis à criança ou jovem em perigo. (Ramião, 2010: 70). São de preferir as medidas a executar no meio natural de vida, sobre aquelas que hajam de ser executadas em regime de colocação, tais como o acolhimento familiar, previsto no artigo $46^{\circ}$ da LPCJP, o acolhimento residencial, previsto no artigo $49^{\circ}$ da mesma lei, e a confiança a instituição, com vista a futura adoção. As primeiras privilegiam e procuram preservar os relacionamentos afetivos e o meio familiar e social da criança ou jovem; as segundas visam, igualmente, assegurar as condições que satisfaçam as necessidades da criança ou jovem, ainda que ausente do seu contexto sociofamiliar natural (Clemente, 2009: 89).

Como último recurso, ficam as medidas de colocação, preferencialmente em acolhimento familiar, ou, quando este não seja possível, residencial. O acolhimento familiar consiste na atribuição da confiança da criança, ou do jovem, a uma pessoa singular ou a uma família, habilitadas para o efeito, visando a sua integração em meio familiar e a prestação de cuidados adequados às suas necessidades e bem-estar e a educação necessária ao seu desenvolvimento integral, considerando-se que constituem uma família duas pessoas casadas entre si, ou que vivam uma com a outra há mais de dois anos, em união de facto, ou parentes que vivam em comunhão de mesa e habitação. $\mathrm{O}$ acolhimento familiar tem lugar quando seja previsível a posterior integração da criança ou jovem numa família ou, não sendo possível, para a preparação da criança ou jovem para a autonomia de vida. Privilegia-se a aplicação da medida de acolhimento familiar sobre a de acolhimento residencial, em especial relativamente a crianças até aos seis anos de idade, salvo quando a consideração da excecional e específica situação da criança ou jovem carecidos de proteção imponha a aplicação da medida de acolhimento residencial; ou quando se constate impossibilidade de facto. A medida de acolhimento residencial consiste na colocação da criança ou jovem aos cuidados de uma entidade que disponha de instalações, equipamento de acolhimento e recursos humanos permanentes, devidamente dimensionados e habilitados, que lhes garantam os cuidados adequados. $\mathrm{O}$ acolhimento residencial tem como finalidade contribuir para a criação de condições que garantam a adequada satisfação de necessidades físicas, psíquicas, emocionais e sociais das crianças e jovens e o efetivo exercício dos seus direitos, favorecendo a sua integração em contexto sociofamiliar seguro e promovendo a sua educação, bem-estar e desenvolvimento integral. O acolhimento residencial constitui a última solução de recurso para a criança ou jovem e só deve ser aplicado quando se tornem inviáveis as restantes medidas, nos termos do artigo $46^{\circ}$, n. $^{\circ} 4$ da LPCJP.

Por sua vez, a medida de confiança a pessoa seleccionada para a adoção, família de acolhimento ou a Casa de acolhimento, com vista a futura adoção, prevista na alínea g) do . $^{\circ} 1$ do artigo $35 .^{\circ}$ da LPCJP, considera-se a executar no meio natural de vida, quando a confiança da criança ou jovem é feita a 
pessoa, enquanto a confiança feita a família ou a Casa de acolhimento é classificada como medida de colocação. A aplicação desta medida é da competência exclusiva dos Tribunais. Resultava do artigo $38 .^{\circ}$ da LPCJP a equiparação desta medida à confiança com vista à futura adoção, prevista no artigo 1978 . $^{\circ}$ do Código Civil, razão pela qual era unânime, na doutrina (Borges, 2011: 172 e Ramião, 2010: 79-81), o entendimento de que esta medida só poderia ser decretada desde que se encontrassem preenchidos os pressupostos de que depende a aplicação do artigo $1978 .^{\circ}$ :

Quando não existam ou se encontrem seriamente comprometidos os vínculos afetivos próprios da filiação, pela verificação objetiva de qualquer das seguintes situações:

a) Se o menor for filho de pais incógnitos ou falecidos;

b) Se tiver havido consentimento prévio para a adoção;

c) Se os pais tiverem abandonado o menor;

d) Se os pais, por ação ou omissão, mesmo que por manifesta incapacidade devida a razões de doença mental, puserem em perigo grave a segurança, a saúde, a formação, a educação ou o desenvolvimento do menor;

e) Se os pais do menor acolhido por um particular ou por uma instituição tiverem revelado manifesto desinteresse pelo filho, em termos de comprometer seriamente a qualidade e a continuidade daqueles vinculos, durante, pelo menos, os três meses que precederam o pedido de confiança.

Hoje, já não poderemos falar de mera equiparação, na medida em que as recentes alterações ao Código Civil trouxeram consigo uma nova redação para este artigo $1978^{\circ}$, que já só se refere precisamente ao processo de promoção e proteção, desde a entrada em vigor do Regime Jurídico das Adoção (Lei n. ${ }^{\circ}$ 143/2015).

Esta medida consiste na colocação da criança, ou do jovem, sob a guarda de candidato seleccionado para a adoção pelo competente organismo de segurança social, ou na colocação da criança, ou do jovem, sob a guarda de instituição, com vista a futura adoção (artigo $38 .^{\circ}$-A da LPCJP - aditado pela Lei n. ${ }^{\circ}$ 31/2003, de 22 de agosto). Tem efeitos idênticos aos da confiança judicial (Coelho e Oliveira, 2006: 282): torna desnecessário o consentimento dos pais do adotando; estes ficam inibidos do exercício das responsabilidades parentais; a aplicação da medida deve respeitar o segredo de identidade dos adotantes e dos pais biológicos do adotado, previsto no artigo $1985 .^{\circ}$ do Código Civil. Esta medida vigorará até que seja decretada a adoção e não está sujeita a revisão, mas nos termos do n. $^{\circ} 2$ do artigo $62 .^{\circ}$-A da LPCJP, a título excecional a medida é revista, nos casos em que a sua execução se revele manifestamente inviável, designadamente quando a criança atinja a idade limite para a adoção 
sem que o projeto adotivo tenha sido concretizado. Não há lugar a visitas por parte da família natural, exceção feita para os casos, devidamente fundamentados, em que, em função da defesa do superior interesse do adotando, possam ser autorizados contactos entre irmãos. Até ser instaurado o processo de adoção, o Tribunal solicita, de seis em seis meses, informação ao organismo de segurança social sobre os procedimentos em curso, com vista à adoção.

\section{0 relatório CASA 2016 e os números das crianças em sistema de acolhimento em Portugal}

Em 2016 estavam em sistema de acolhimento 8.175 crianças. Destas, 2.396 ingressaram neste sistema no próprio ano enquanto que as restantes transitaram de anos anteriores. Cessou neste ano a situação de acolhimento para 2.513 crianças. Nos últimos anos é notório o predomínio da aplicação de medidas de promoção e proteção a executar em meio natural de vida, com especial incidência a aplicação da medida de apoio junto dos pais (ISS: 2017, 10-11). O número de crianças e jovens em situação de acolhimento regista uma tendência de diminuição no último ano, após um pequeno crescimento registado nos anos de 2014 e 2015 (ISS: 2017, 17). Infelizmente, cerca de 50\% das crianças que entretanto ingressaram no sistema de acolhimento começaram por beneficiar de medidas aplicadas em meio natural de vida, sem que o desenvolvimento dos respetivos planos de intervenção individuais tivesse garantido a redução ou eliminação do perigo instalado (ISS: 2017, 53). O maior número de casos de acolhimento verifica-se nos distritos de Lisboa e Porto (ISS: 2017, 19).

Em 2016, apenas 261, do total de crianças em situação de acolhimento, se encontravam colocadas em família de acolhimento. Dentro destas, em termos etários, predominavam os adolescentes, com idades superiores aos 12 anos.

No que respeita às causas que fundamentaram a decisão de acolhimento, verifica-se na esmagadora maioria dos casos a negligência, nas suas diversas formas, como causa mais comum, seguindo-se as situações de maus tratos psicológicos e físicos e os abusos sexuais (ISS: 2017, 48).

Em 2016 o principal motivo da cessação da situação de acolhimento deveu-se ao regresso ao meio natural de vida da criança, pela reintegração junto dos pais, tios, avós, irmãos, família adotante, pessoa ou família idónea ou apadrinhamento civil, o que foi possível, por isso, em $78 \%$ dos casos. Todavia, em $22 \%$ dos casos, a solução passou pela transição para respostas institucionais (ISS: 2017, 85). Em muitas situações, após a cessação do acolhimento, foram aplicadas subsequentemente outras medidas de promoção e proteção ou medida tutelar ou de outra natureza jurídica, a cerca de $70 \%$ das crianças. Nos restantes casos não veio a ser aplicada qualquer outra medida (ISS: 2017, 88).

Para os profissionais que contactam diretamente com a realidade das crianças acolhidas torna-se claro que, numa perspetiva evolutiva, as crianças 
que eram acolhidas há uma década são consideravelmente diferentes das que são acolhidas hoje: "estão mais crescidas, mais complexas, mais exigentes e chegam cada vez mais tarde ao sistema de acolhimento" (ISS: 2017, 94). Por essa razão, as respostas do acolhimento têm também que evoluir. "pretende-se um sistema com mais opções de resposta de cariz familiar, permeável às necessidades das crianças e jovens, e por isso dotado de modelos especializados e de cuidadores continuamente qualificados.” (ISS: 2017, 94)

O instituto do apadrinhamento civil poderá ir ao encontro destas expetativas de desinstitucionalização das crianças lançadas no sistema de acolhimento.

\section{0 apadrinhamento civil como alternativa ao acolhimento perma- nente de crianças e jovens}

As medidas previstas na LPCJP têm natureza transitória, encontrando-se consagrados limites temporais relativamente curtos para a aplicação das mesmas. Em casos mais difíceis, ou extremos, poderá justificar-se uma intervenção de cariz mais duradouro, que poderá passar então pela necessidade de regulação do exercício das responsabilidades parentais, pela alteração da regulação das mesmas, pela inibição do exercício das responsabilidades parentais e consequente instituição da tutela, ou de apadrinhamento civil, em favor do menor, ou mesmo pela adoção.

O conceito de projeto de vida deve ser entendido como um guia, uma referência para orientar a realidade pessoal de cada uma das crianças e jovens em acolhimento, devendo ser desenhado em função das suas necessidades, da idade, das caraterísticas, com respeito pelas suas histórias de vida e respetivos contextos. Deve ser construído com rigor e profissionalismo, com participação da criança ou jovem e sua família, executado com cuidado e afeto, de modo a fomentar o desenvolvimento integral da criança ou do jovem (ISS: 2017, 65). Este projeto de vida pode passar pelo apadrinhamento civil.

Em 2016, do total de crianças em situação de acolhimento, os seus projetos de vida individuais passavam maioritariamente pela reintegração na família nuclear ou pela autonomização, respetivamente em 2.672 e 2.690 casos (ISS: 2017, 67). Em 633 casos o projeto de vida das crianças passava pelo acolhimento permanente, residencial ou familiar. Apenas em escassos 34 casos se vislumbrava como solução de longa duração o recurso ao apadrinhamento civil. A inserção em outra família, a tutela e a adoção são outros caminhos possíveis em algumas hipóteses (ISS: 2017, 81).

$\mathrm{O}$ instituto do apadrinhamento civil encontra os seus antecedentes próximos em soluções adotadas em países como a França, a Alemanha, ou a Inglaterra, em que a criança é confiada a famílias, ou pessoas a quem cabe o exercício das responsabilidades parentais próprias dos pais. A designação deste instituto procede do entendimento do legislador quanto às expressões "apadrinhamento civil", "padrinho" e "madrinha", que considera apresentarem 
vantagem sobre outras quaisquer, na medida em que são conhecidas pela população com um sentido relativamente aproximado do que se pretende estabelecer na lei civil: o padrinho ou madrinha são substitutos dos pais no cuidado das crianças e dos jovens, sem pretenderem fazer-se passar por pais, como pode ler-se na Exposição de Motivos da Proposta de Lei n. ${ }^{\circ}$ 253/X. Este instituto decorre da Lei n. ${ }^{\circ}$ 103/2009, de 11 de setembro, regulamentada pelo DecretoLei n. ${ }^{\circ}$ 122/2010, de 27 de outubro, na redação que lhe foi conferida pela Lei n. ${ }^{\circ}$ 141/2015, de 8 de setembro, para o Apadrinhamento Civil, e pela Lei n. $2 / 2016$, de 29 de fevereiro, para a sua regulamentação. Destina-se àquelas crianças para as quais a adoção não é viável, ou não é possível.

Durante o primeiro ano de funcionamento (2006/2007), o Observatório Permanente da Adoção formulou a necessidade de encontrar novas formas de colocação definitiva das crianças e dos jovens, que se acrescentem ao regresso à família biológica e à adoção, pois que estas duas soluções conhecidas não têm sido suficientes para evitar que as crianças e os jovens permaneçam internados demasiado tempo em instituições de acolhimento. Melo (2010: 226-227) afirma precisamente que "em relação àquelas crianças ou jovens cujo vínculo com a família biológica não esteja completamente comprometido ou que, por motivos vários, como a idade, o passado problemático, ou a inexistência de candidatos a adotantes tornem improvável a adoção, a lei não previa até aqui outro caminho que não passasse pela institucionalização."

$\mathrm{O}$ apadrinhamento civil visa, por isso, permitir às crianças cujos progenitores, por qualquer razão, não exerçam da forma mais adequada as suas responsabilidades parentais, uma alternativa ao acolhimento residencial e o acolhimento num ambiente familiar que favoreça o seu bem-estar e desenvolvimento.

Nesse sentido se têm pronunciado os tribunais, como é exemplo o Acórdão da Relação de Lisboa, de 22 de novembro de 2012: "VI - O apadrinhamento civil é um vínculo jurídico que, em regra, concilia a manutenção de vínculos biológicos com os vínculos afetivos típicos do apadrinhamento, constituindo no nosso ordenamento jurídico um meio apto a proporcionar uma solução de proteção a crianças em perigo, de caráter definitivo, sem ser a confiança para adoção.”

Por sua vez, na Exposição de Motivos da Proposta de Lei n. ${ }^{\circ}$ 253/X pode ler-se que:

O apadrinhamento civil visa, sobretudo, promover a desinstitucionalização, através da constituição de uma relação para-familiar tendencialmente permanente, destinada às crianças e jovens que não são encaminhados para a adoção, ou não são adotados. Deseja-se que os primeiros beneficiários do regime sejam as crianças e jovens que estejam acolhidos em instituição, embora não se exclua que outras crianças $e$ 
jovens sejam apadrinhados, na sequência da revisão de outra medida, ou mesmo antes da aplicação de qualquer medida.

Este modelo assenta num contrato estabelecido com os pais, homologado pelo Tribunal, ou por decisão do Tribunal, através do qual o padrinho civil fica habilitado a exercer o essencial das responsabilidades parentais, em diálogo com os pais, relativamente aos aspetos mais relevantes da vida e da pessoa da criança (Clemente: 2009, 106). O apadrinhamento civil pode constituir-se em qualquer altura de um processo de promoção e proteção, ou de um processo tutelar cível e quando tiver lugar após a aplicação de uma medida de promoção e proteção, ou após uma decisão judicial sobre a regulação do exercício das responsabilidades parentais, com que se mostre incompatível, determina necessariamente a sua cessação.

O apadrinhamento civil é uma relação jurídica tendencialmente de caráter permanente, que se estabelece entre uma criança, ou jovem e uma pessoa singular ou uma família que exerça os poderes e deveres próprios dos pais e que com ele estabeleçam vínculos afetivos que permitam o seu bem-estar e desenvolvimento. O artigo $7^{\circ}$ da Lei do Apadrinhamento Civil determina que " 1 - Os padrinhos exercem as responsabilidades parentais, ressalvadas as limitações previstas no compromisso de apadrinhamento civil ou na decisão judicial”.

Esta relação é constituída por homologação, ou decisão judicial e sujeita a registo civil, nos termos do artigo $2 .^{\circ}$ da Lei n. ${ }^{\circ}$ 103/2009, de 11 de setembro. É uma nova relação jurídica cuja natureza é discutida. Dias (2012: 187) problematiza se a relação de apadrinhamento civil constituirá uma nova relação jurídica familiar. E Pinheiro (2008: 723) considera que sim, mas o legislador definiu-a como uma relação para-familiar. $O$ apadrinhamento civil surge ao lado da tutela e da adoção restrita, constituindo um minus em relação a esta última, entretanto desaparecida do nosso ordenamento jurídico, por força da Lei n. ${ }^{\circ}$ 143/2015, de 8 de setembro, e um plus em relação à primeira.

A tutela ocupa determinado espaço jurídico, tradicional, que pressupõe a ausência dos pais e não implica uma dimensão afetiva e emocional, como a que se defende para o apadrinhamento civil. O Observatório Permanente da Adoção (2011, 5-7) afirma que o apadrinhamento assenta sobretudo numa relação de afeto, sendo a integração em ambiente familiar uma nota distintiva dessa figura, uma vez que a tutela não impõe essa integração. O padrinho é mais do que um tutor, ao pretender-se que se estabeleça uma relação quase-familiar, que não se extingue com a maioridade, afigurando-se como tendencialmente perpétua, exceção feita para as hipóteses de revogação, prevista nos artigos $24 .^{\circ}$ e $25 .^{\circ}$ da Lei do Apadrinhamento Civil.

Tanto assim é que, entre padrinho e afilhado se estabelece uma obrigação recíproca de alimentos, equiparando-se os padrinhos aos ascendentes em primeiro grau do afilhado, para efeitos da obrigação de lhe prestar alimentos, 
sendo precedidos pelos pais, deste que se encontrem em condições de satisfazer tal encargo e o afilhado, do mesmo modo, é considerado descendente em primeiro grau dos padrinhos, para o efeito da obrigação de lhes prestar alimentos, também precedido pelos filhos destes que estejam em condições de satisfazer o encargo. Por outro lado, outro traço distintivo do apadrinhamento civil, em relação à tutela, reside no facto de que não impende sobre o padrinho a obrigação de relacionar os bens do afilhado e de prestar contas, que sempre existe nas hipóteses de tutela, desde que os pais do afilhado sejam vivos, conhecidos e não estejam inibidos do exercício das responsabilidades parentais, como resulta, a contrario sensu, do n. 3 do artigo $7 .^{\circ}$ da Lei do Apadrinhamento Civil.

O padrinho é menos que um adotante restrito, uma vez que os requisitos para se efetuar o apadrinhamento civil são menos exigentes dos que se impunham para a adoção restrita, (quando esta ainda existia no nosso ordenamento jurídico) designadamente no que concerne à dispensa do consentimento para a constituição do apadrinhamento civil, que se encontra aqui facilitada, nos termos do artigo $14 .^{\circ}$, n..$^{\circ}$, da Lei do Apadrinhamento Civil. Por outro lado, no apadrinhamento civil não há lugar à atribuição ao afilhado dos apelidos do padrinho, ao contrário do que acontecia na adoção restrita, nem direitos sucessórios recíprocos, sendo a revogação do vínculo do apadrinhamento civil mais fácil do que se verificava para a adoção restrita.

O instituto do apadrinhamento civil, pelas suas características, apresenta grandes potencialidades na diminuição do número de crianças em situação de acolhimento, uma vez que em relação a muitas destas é extremamente difícil que se encontrem verificados os pressupostos da adoção (Ferreira, 2012: 411-424).

Poderão apadrinhar, os maiores de 25 anos, desde que previamente habilitados para o efeito, podendo, todavia, ser designados como padrinhos os familiares, a pessoa idónea ou a família de acolhimento a quem a criança ou o jovem tenha sido confiado no processo de promoção e proteção ou o tutor.

A habilitação dos padrinhos consiste, na certificação de que a pessoa singular ou os membros da família que pretendem apadrinhar uma criança ou jovem possuem idoneidade e autonomia de vida que lhes permitam assumir as responsabilidades próprias do vínculo de apadrinhamento civil. A habilitação dos padrinhos cabe ao organismo competente da segurança social. Mediante acordos de cooperação celebrados com o organismo competente da segurança social, as instituições que disponham de meios adequados podem adquirir a legitimidade para designar e habilitar padrinhos. Constituem fatores de habilitação, nos termos do artigo $3^{\circ}$ do Decreto-Lei n. ${ }^{\circ}$ 121/2010, de 27 de Outubro: a personalidade, maturidade, capacidade afetiva e estabilidade emocional; as capacidades educativas e relacionais para responder às necessidades específicas da criança ou do jovem e para promover o seu desenvolvimento integral; as condições de higiene e de habitação; a situação económica, profissional e 
familiar; a ausência de limitações de saúde que impeçam de prestar os cuidados necessários à criança ou ao jovem; a motivação e expectativas para a candidatura ao apadrinhamento civil; a disponibilidade para cooperar com o apoio previsto na Lei do Apadrinhamento Civil, a prestar pelas Comissões de Proteção e instituições que possuam os meios adequados para o efeito, por delegação da entidade competente da Segurança Social, com vista à criação ou intensificação das condições necessárias para o êxito da relação de apadrinhamento e à avaliação do êxito da relação de apadrinhamento, do ponto de vista do interesse do afilhado; a disponibilidade para receber a formação que os organismos competentes vierem a proporcionar; a disponibilidade para respeitar os direitos dos pais ou de outras pessoas relevantes para a criança ou o jovem; a capacidade e disponibilidade para promover a cooperação com os pais na criação das condições adequadas ao bem-estar e desenvolvimento da criança ou do jovem; a posição dos membros do agregado familiar dos candidatos, e por outros familiares com influência na dinâmica da família, face ao vínculo do apadrinhamento civil.

A habilitação dependerá, ainda, de o candidato ou de qualquer das pessoas que com ele coabitem não terem sido condenados, por sentença transitada em julgado, pelos crimes previstos no artigo $152^{\circ}$ do Código Penal (Violência Doméstica), no artigo $152^{\circ}$-A (Maus Tratos) e crimes contra a liberdade e autodeterminação sexual. O candidato a padrinho não poderá, igualmente, estar inibido do exercício das responsabilidades parentais nem ter o seu exercício limitado nos termos do artigo 1918. ${ }^{\circ}$ do Código Civil.

Com a entrada em vigor da Lei n. ${ }^{\circ} 2 / 2016$, eliminadas que foram as discriminações no acesso à adoção, apadrinhamento civil e demais relações jurídicas familiares, impõe-se que todas as disposições legais relativas ao apadrinhamento civil sejam agora interpretadas em consonância com esta lei, independentemente do sexo dos cônjuges, pondo-se termo à querela doutrinal sobre a admissibilidade do apadrinhamento civil por casais homossexuais.

Mas a lei do apadrinhamento civil apresenta fragilidades, tais como a obrigatoriedade da manutenção dos laços com a família de origem, exceção feita, para os casos previstos no n. ${ }^{\circ} 2$ do artigo $8^{\circ}$ da Lei do Apadrinhamento Civil, segundo o qual, o tribunal poderá estabelecer limitações aos direitos dos pais de contacto e visita dos filhos, quando os mesmos ponham em risco a segurança ou a saúde física ou psíquica da criança ou do jovem ou comprometam o êxito da relação de apadrinhamento civil. Esta regra da obrigatoriedade da manutenção destes laços é encarada pelos especialistas como tendo um potencial efeito perturbador, que o contacto com duas famílias poderá ter na criança ou no jovem apadrinhado. Villas-Boas (2011) sustenta a sua posição, socorrendo-se do fracasso da adoção restrita, defendendo que "poucos serão os que querem adotar uma criança, mantendo a família de origem por perto”. Muito embora a adoção constitua uma relação jurídica diversa, esta crítica não 
se revela desprovida de sentido. Poderá, com efeito, constituir um entrave ao recurso mais frequente ao instituto.

“Atualmente assistimos, no direito da família, a vários fenómenos que nos indicam que a sociedade não é altruísta e, salvo algumas exceções, se alguém faz algo em benefício de outrem, não o faz sem também tirar algum proveito próprio. Para a implementação do apadrinhamento civil é necessário que haja pessoas dispostas a assumir o papel de padrinhos.” (Dias, 2012: 190)

Os obstáculos apresentados por estes dois autores não nos parecem de cariz intransponível: em primeiro lugar, porque resulta claro da letra e do espírito da lei que os padrinhos não pretendem ocupar o lugar dos pais; em segundo lugar, porque depositamos mais confiança na espécie humana do que Dias (2012: 190) e acreditamos que o Direito da Família não se reduz a uma lógica de custos-benefícios e que a lacuna da Lei do Apadrinhamento Civil na previsão de uma qualquer prestação social, como contrapartida para o padrinho, não constituirá fator decisivo na dissuasão da aplicação do instituto. Recorde-se, por exemplo, que o instituto da adoção, nos dias de hoje, é concebido em ordem à prossecução do superior interesse da criança e não em nome da realização pessoal dos adotantes, mas não deixa, por essa razão, de ser um instituto bem-sucedido, no nosso ordenamento jurídico. Os adotantes não têm direito, nessa qualidade, a quaisquer prestações sociais. Por outro lado, os papéis sociais do padrinho e da madrinha encontram-se profundamente sedimentados na sociedade portuguesa.

Reconhecemos, todavia, como defendem Dias (2012: 190) e Branco (2011), muito embora, os padrinhos e os afilhados gozem dos direitos às prestações sociais, nos mesmos termos que os pais e os filhos, e o estabelecimento de uma retribuição mensal, para os padrinhos, à semelhança do que se verifica como com as famílias de acolhimento, constituiria um estímulo ao Apadrinhamento Civil.

\section{Notas conclusivas}

O instituto do apadrinhamento civil é uma opção ainda por descobrir pelos potenciais padrinhos e afilhados e pelos profissionais com responsabilidades no processo de apadrinhamento. Torna-se necessário divulgar o instituto, no plano do Direito, dinamizar a sua aplicação, para que o Apadrinhamento Civil possa, na prática, traduzir-se numa verdadeira alternativa ao acolhimento residencial, como já o é do ponto de vista legal.

É uma matéria pouco tratada pela doutrina, praticamente desconhecida da jurisprudência e ainda não testada pelas famílias (Guimarães, 2012: 480). Esta convicção sai reforçada pelos números disponibilizados pelo Instituto de Segurança Social, que indicavam que, em 2011, só haviam sido realizadas onze entrevistas a candidatos a padrinhos, tendo sido formalizadas seis 
candidaturas e habilitado um padrinho. Nos primeiros dez meses de 2012, foram realizadas nove entrevistas, formalizadas seis candidaturas e habilitados quatro padrinhos, estando dois candidatos inscritos em bolsa. Apesar de haver poucos candidatos, existem crianças para serem apadrinhadas: $70 \mathrm{em} 2011 \mathrm{e}$ 58 em 2012. Em 2015 foram apadrinhadas 32 crianças (Ferreira: 2017). Em 2016, apenas em escassos 34 casos se vislumbrava como solução de longa duração o recurso ao apadrinhamento civil (ISS, 2017). No presente, não encontramos disponíveis estudos ou estatísticas que nos permitam inferir do sucesso ou insucesso na aplicação deste instituto. Desde que o instituto foi criado, terão beneficiado da sua aplicação cerca de 320 crianças, o que é muito pouco, se tivermos em mente as suas potencialidades. A carência de estudos sobre o tema traduzirá, talvez, o pouco interesse e o pouco investimento que se tem dedicado ao Apadrinhamento Civil. Urge, em nosso ver, o desenvolvimento de uma profunda reflexão dos poderes públicos sobre o que se quer que este instituto seja. Um alargamento do recurso ao Apadrinhamento Civil passará por um reforço da sensibilização dos profissionais desta área para as potencialidades do instituto, através da formação. Por outro lado, a conceção de campanhas de divulgação junto da população em geral poderia também ser vantajosa na consecução deste desiderato, e finalmente, a criação de alguma espécie de incentivo, fiscal, e/ou de apoio financeiro, poderia também revelar-se positiva para o incremento do número de apadrinhados civis.

É seguro, porém, que as leis só mostram o que valem no momento da sua aplicação (Oliveira, 2011). Por isso, só o decurso do tempo dirá se o instituto teve o acolhimento desejado e atingiu os objetivos a que se propunha. Por agora, será legítimo afirmar que se encontra muito aquém das expectativas e corre um risco de morte antecipada... Fazemos votos para que ainda haja salvação para o Apadrinhamento Civil e para que seja possível que este constitua uma alternativa viável à diminuição do drama destas crianças e jovens tão fragilizadas pelo percurso do acolhimento residencial. 


\section{Referências bibliográficas}

ALFAIATE, Ana Rita e RIBEIRO, Geraldo Rocha (2013), “Reflexões a propósito do apadrinhamento civil”, Revista do CEJ.

LFAIATE, Ana Rita e RIBEIRO, Geraldo Rocha (2016), "Seis anos depois: análise do impacto do apadrinhamento civil em matéria de protecção dos afectos das crianças e jovens em Portugal”, in Cuidado e Afetividade, Projeto Brasil/Portugal - 2016/2017 (org. PEREIRA, Tânia da Silva, OLIVEIRA, Guilherme de, COLTRO, Antônio Carlos Mathias), Brasil, Editora Atlas, Setembro.

BOLIEIRO, Helena e GUERRA, Paulo (2014), A criança e a família-uma questão de direito(s), 2. ${ }^{\text {a }}$ Edição, Coimbra Editora.

BORGES, Beatriz (2011), Proteção de Crianças e Jovens em Perigo - Comentários e Anotações à Lei . $^{\circ} 147 / 99$, de 1 de Setembro, $2^{\text {a }}$ edição, Coimbra: Almedina.

BRANCO, Lídia (s/d), Apadrinhamento civil. O Simplex da adopção?, [Online] disponível em http://www.ionline.pt [consultado em julho de 2013].

BRAVO, José António Dias (2002), Nota Final in O Direito Tutelar de Menores - o sistema em mudança, Coimbra: Coimbra Editora.

CADETE, Ana Lídia (2013), "O apadrinhamento civil: as potencialidades do instituto - o caso do Bruno", Lex Familiae, Ano 10, n. ${ }^{\circ}$ 20, Coimbra Editora.

CARREIRA, João Paulo Ferraz (2002), As situações de perigo e as medidas de proteção, in Direito Tutelar de Menores, o sistema em mudança, Coimbra: Coimbra Editora.

ClEMENTE, Rosa (2009), Inovação e Modernidade no Direito de Menores. A perspetiva da Lei de Proteção de Crianças e Jovens em Perigo, Coimbra: Coimbra Editora.

COELHO, Francisco Pereira, OLIVEIRA, Guilherme de (2017), Direito da Família, Adoção e Apadrinhamento civil, Imprensa da Universidade on-line.

COELHO, Francisco Pereira e OLIVEIRA, Guilherme de (2011), Curso de Direito da Família, Vol. I, Introdução, Direito Matrimonial, 4ª edição, reimpressão, Coimbra: Coimbra Editora, 2011.

COELHO, Francisco Pereira e OLIVEIRA, Guilherme de (2006), Curso de Direito da Família, vol. II, Coimbra: Coimbra Editora.

DIAS, Cristina Araújo (2012), Algumas Notas em torno do Regime Jurídico do Apadrinhamento Civil, in Estudos em Homenagem ao Professor Doutor Heinrich Ewald Hörster, Coimbra: Almedina, p. 161-195.

FERREIRA, Maria Elisabete (2012), Algumas notas sobre o regime jurídico do Apadrinhamento Civil, in Estudos em Homenagem ao Professor Doutor Heinrich Ewald Hörster, Coimbra: Almedina, p. 411- 424.

FERREIRA, Maria Elisabete (2016), Violência parental e intervenção do Estado: a questão à luz do direito português, Porto: Universidade Católica.

FERREIRA, Sandra (2017), Há 320 crianças e jovens que vivem com padrinhos civis, [Online] disponível em https://portal.oa.pt/comunicacao/imprensa/2017/01/16/familias-ha-320-criancas-e-jovens-que-vivem-com-padrinhos-civis-paginas-4-e-5/ [consultado em 30 de maio de 2018]).

GUIMARÃES, Raquel (2012), O novo regime português do "Apadrinhamento Civil”, in Estudos em Homenagem ao Professor Doutor Heinrich Ewald Hörster, Coimbra: Almedina, p. 479-498.

INSTITUTO DA SEGURANÇA SOCIAL(2017), CASA 2016 - Relatório de Caracterização Anual da Situação de Acolhimento das Crianças e Jovens, [Online] disponível em http:// www.seg-social.pt/noticias/-/asset_publisher/9N8j/content/id/15294742, [consultado em agosto de 2017]. 
MARTINHO, Edmundo (2009), Posfácio, in Inovação e Modernidade no Direito de Menores. A perspetiva da Lei de Proteção de Crianças e Jovens em Perigo, Coimbra: Coimbra Editora.

MELO, Helena et al. (2010), Poder Paternal e Responsabilidades Parentais, $2^{\mathrm{a}}$ edição revista, atualizada e aumentada, Lisboa: Quid Juris?.

OLIVEIRA, Guilherme de (2008), "Apadrinhamento civil: uma iniciativa portuguesa, com certeza”, Revista do Advogado, Ano 28, n’. 101, dezembro de 2008.

OBSERVATÓRIO PERMANENTE DA ADOÇÃO (2011), Regime Jurídico do Apadrinhamento Civil Anotado, Coimbra: Coimbra Editora.

PASSINHAS, Sandra (2012), "O apadrinhamento civil: uma nova figura no Direito Português”, Revista Fórum de Direito Civil-RFDC, Belo Horizonte, Ano 1, n. ${ }^{\circ}$ 1, setembro - Dezembro.

PINHEIRO, Jorge Duarte (2008), O Direito da Família Contemporâneo, Lisboa: AAFDL.

PINTO, António Clemente (2011), Guia de Procedimentos do Processo de Promoção e Protecção (Regime Jurídico do Apadrinhamento Civil), 3. ${ }^{a}$ edição, Almedina.

RAMIÃO, Tomé d'Almeida (2010), Lei de Proteção de Crianças e Jovens em Perigo Anotada e Comentada, $6^{a}$ edição (atualizada e aumentada), Lisboa: Quid Juris?.

RAMIÃO, Tomé d'Almeida (2011), Apadrinhamento Civil Anotado e Comentado, Lisboa: Quid Juris?.

RODRIGUES, Anabela Miranda, e FONSECA, António Carlos Duarte (2003), Comentário da Lei Tutelar Educativa, Coimbra: Coimbra Editora.

VILLAS-BOAS (2010), Apadrinhamento civil. O Simplex da adopção?, [Online] disponível em http://www.ionline.pt [consultado em julho de 2013]. 